\title{
Os efeitos da covid -19 na educação básica de Mato Grosso do Sul: como a rede estadual de ensino enfrenta a pandemia?
}

\author{
The effects of covid -19 in basic education in Mato Grosso do Sul: \\ how does the state education system face the pandemic? \\ Les effets du covid -19 sur l'éducation de base au Mato Grosso do Sul: \\ comment le réseau éducatif de l'état fait-il face à la pandémie?
}

\author{
Eleida da Silva Arce Adamiski ${ }^{1}$ \\ Universidade Estadual de Mato Grosso do Sul \\ Marcos Antônio Bessa-Oliveira ${ }^{2}$ \\ Universidade Estadual de Mato Grosso do Sul
}

\begin{abstract}
Resumo: Considerando a crise sanitária mundial causada pela pandemia da COVID-19 e, como as medidas de enfrentamento a doença vem atingindo diretamente a educação, este estudo pretende refletir e discutir, por meio da epistemologia do pensamento descolonial, a situação vigente da educação básica de Mato Grosso do Sul, mais especificamente a atuação do professor da rede estadual nas aulas não presenciais. Para tanto, temas como a organização de aulas remotas, a exclusão escolar de estudantes inviabilizados pelo não acesso à escola e a equipamentos tecnológicos, a falta de domínio para uso de novos recursos eletrônicos por parte dos professores, o excesso de atividades em frente a computadores que faz com que os corpos sejam diretamente atingidos e o iminente risco a saúde mental dos envolvidos com processos educacionais, nos fazem refletir na educação que precisamos ter no pós-pandemia.
\end{abstract}

Palavras-chave: Educação básica do Mato Grosso do Sul. Professores e Estudantes. Covid-19.

\begin{abstract}
Considering the global health crisis caused by the COVID-19 pandemic and, as the measures to fight the disease have directly affected education, this study intends to reflect and discuss, through the epistemology of decolonial thinking, the current situation of basic education in Mato Grosso do Sul, more specifically the role of the state school teacher in nonpresential classes. Therefore, topics such as the organization of remote classes, the school exclusion of students that were unfeasible by the lack of acess to school or to technological equipment, the lack of mastery in the use of new electronic resources by teachers, the excess of activities in front of computers that cause bodies to be directly affected and the imminent risk to the mental health of those involved in educational processes, make us reflecting on the education we need to have in the post-pandemic.
\end{abstract}

Keywords: Basic education in Mato Grosso do Sul. Teachers and Students. Covid-19.

\footnotetext{
${ }^{1}$ Mestranda do Programa de Pós-Graduação Stricto Sensu em Educação da Universidade Estadual de Mato Grosso do Sul. Coordenadora de Políticas para o Ensino Fundamental da Secretaria de Estado de Educação de Mato Grosso do Sul, Campo Grande - MS, Brasil. E-mail: eleidaarce@gmail.com. Lattes: http://lattes.cnpq.br/6295529806301039. ORCID: https://orcid.org/o000-0001-8540-0174.

${ }^{2}$ Pós-Doutor pela Faculdade de Artes, Letras e Comunicação, Universidade Federal de Mato Grosso do Sul. Professor na Universidade Estadual de Mato Grosso do Sul. Campo Grande - MS, Brasil. E-mail: marcosbessa2001@gmail.com. Lattes: http://lattes.cnpq.br/7724599673552418. ORCID: https://orcid.org/o000-0002-4783-7903.
} 
Resumen: Considérant la crise sanitaire mondiale causée par la pandémie de COVID-19 et, comme les mesures prises pour faire face la maladie ont directement affecté l'éducation, cette étude vise à réfléchir et à discuter, à travers l'épistémologie de la pensée décoloniale, la situation actuelle de l'éducation de base dans Mato Grosso do Sul, plus précisément le rôle de l'enseignant de l'école publique dans les classes non-présentiales. Ainsi, des enjeux tels que l'organisation des classes à distance, l'exclusion des élèves de l'école rendue invisible par l'absence d'accès aux équipements scolaires et technologiques, le manque de maîtrise de l'utilisation des nouvelles ressources électroniques par les enseignants, l'excès d'activités devant les ordinateurs qui affectent directement les corps et le risque imminent pour la santé mentale des personnes impliquées dans les processus éducatifs, nous font réfléchir sur l'éducation que nous devons avoir dans l'après-pandémie.

Mots-clés: Éducation de base au Mato Grosso do Sul. Enseignants et étudiants. Covid 19.

\section{Introdução - A escola no lar e o lar é a escola}

Pensar descolonialmente é acreditar, ainda que utopicamente - como pensam alguns ser a única pretensão do pensamento descolonial -, que há no ar uma novidade diferente para ver o mundo de uma lógica outra ainda "desse" mundo. (BESSA-OLIVEIRA, Educação, Tecnocolonialidade, Docência Remota छ̊ a Covid-19, p. 79.

Esta discussão está ancorada em uma lógica epistemológica descolonial e visa refletir o trabalho da Secretaria de Estado de Educação de Mato Grosso do Sul (SED-MS) e suas escolas, em relação ao momento de isolamento social na educação brasileira, em especial na Rede Estadual de Ensino de Mato Grosso do Sul, em virtude da Pandemia da Covid-19 e a situação da saúde mental dos professores, frente ao novo desafio apresentado: o ensino remoto.

Professores e estudantes passam a estudar por atividades remotas, ou seja, o lar passa a ser a escola, e este passa a ser o mundo de cada um isolado socialmente. Com o objetivo de auxiliar nossas discussões no pensamento descolonial, usaremos autores como Bessa-Oliveira, Faria, Faro, Boaventura de Souza Santos, dentre outros pesquisadores do referido pensamento, além de documentos oficiais expedidos pelo Governo Federal e Estadual de MS.

A opção pelo pensamento descolonial, e não por outro de perspectiva moderna ou pós-moderna, ancora-se na possibilidade de vislumbrar relações até então não observadas no tratamento das políticas governamentais, das tecnologias, dos direitos e deveres, dentre outros aspectos, acerca da educação. A priori, porque o pensamento descolonial defende uma ideia de educação em política, contrariando as atuais "soluções" políticopartidárias muitas vezes presentes na educação. 
O primeiro momento deste artigo vem recordar como se estabeleceu o início desta história, partindo da China e até a chegada ao Brasil. Em seguida, trataremos da organização de Mato Grosso do Sul e as medidas de prevenção voltadas à educação. Abordaremos também a organização das escolas da Rede Estadual de Ensino e algumas breves reflexões sobre a saúde mental dos professores.

Nesse ínterim, evidenciar-se-ão, de algum modo, as políticas públicas estabelecidas e adotadas pelo Estado e escolas, respectivamente, bem como, de que forma tornarão "transparentes" as relações entre estudante, escola, família e tecnologias. Outrossim, tratativas que emergirão no que se refere às insanidades provocadas aos professores desde que um vírus foi tratado com perspectivas políticas que não se preocuparam em separar vírus e sociedade, com a intenção de preservar vidas.

Por fim, abordaremos novas experivivências que a educação deve incorporar em seu cotidiano pós-pandemia. Conforme ressalta Walter Mignolo (2008, p. 305), "Precisamos desatar o nó, aprender a desaprender, e aprender a reaprender a cada passo”. Assim, ao retornarmos "ao normal", que este seja um "novo normal”, mais humano, mais coerente, mais respeitoso com o outro, com a natureza, com tudo e todos que nos cercam.

Com tal característica, que venha um "novo normal” em que a educação consiga cumprir o seu papel de formação em detrimento da deformação que muitos vêm incorporando às salas de aulas por meio de políticas que melhor controlam corpos que precisam de libertação para conviver. Em outras palavras, a ideia é que a educação possa vir a ser um lugar de constituição de conhecimentos e saberes em diálogo para fortalecer a escola como espaço social de produção de conhecimento, não coercitiva de políticas, direitos, religiões, gêneros, culturas, dentre outras particularidades que as políticas ditas "Sem Partido" e "Sem Religião", que na verdade é um Projeto de Lei a fim de instituir o "Programa Escola sem Partido": projetos que ressaltam, o “com” partido ou “com” religião específicos que tanto querem estabelecer. ${ }^{3}$

\section{A chegada da covid-19 no mundo: quando passamos a ver o mundo pela janela real ou virtual}

No dia 31 de dezembro de 2019, a Organização Mundial da Saúde (OMS) foi alertada sobre vários casos de pneumonia na cidade de Wuhan, província de Hubei, na República Popular da China. Alguns dias depois, as autoridades chinesas anunciaram a descoberta de uma nova versão do coronavírus, nomeada posteriormente de SARS-COV-2 (Síndrome Respiratória Aguda Grave do Coronavírus 2). Este vírus era o causador da COVID-19, doença

\footnotetext{
${ }^{3}$ Maiores esclarecimentos, por meio da leitura na integra do "Projeto de Lei", acerca desta última questão estão disponíveis em: https://www.camara.leg.br/proposicoesWeb/prop_mostrarintegra?codteor $=1707037 \&$ filename $=$ PL +2 . Acesso em: 04 jun 2021.
} 
que se espalhara em proporções alarmantes, provocando contágio rápido e consequentemente crescente número de óbitos. Tal situação incitou declaração de Emergência de Saúde Pública Importância Internacional por parte da OMS no dia 30 de janeiro de 2020. E, logo depois, esta atingiu o status de Pandemia.

Em 11 de março de 2020, a COVID-19 foi caracterizada pela OMS como uma pandemia. O termo "pandemia" se refere à distribuição geográfica de uma doença e não à sua gravidade. A designação reconhece que, no momento, existem surtos de COVID-19 em vários países e regiões do mundo (OPAS, 2020, s.p.).

Tais decisões demandaram resposta internacional coordenada e imediata, isto é, necessidade de ações juntamente com outros países para o enfrentamento da situação emergencial. Assente nisso, começamos a acompanhar diariamente nos noticiários como a COVID-19 se espalhava pelo mundo, ocasionando o adoecimento de milhares de pessoas. Hospitais passaram a ficar sobrecarregados com suas equipes cansadas e governantes foram obrigados a tomarem decisões radicais para o enfretamento da doença.

No Brasil, o primeiro caso de Covid-19 foi confirmado no dia 26 de fevereiro de 2020. O paciente era um homem que esteve na Itália e se recuperou da doença. Por conseguinte, se iniciou os esboços de um plano de enfrentamento à Pandemia como combate à circulação do vírus que, a princípio, se pensava que não se desenvolveria, devido as características climáticas do Brasil. A partir da constatação do primeiro caso, sabíamos que não ficaríamos alheios às circunstâncias pandêmicas. Só não pudemos prever ali que nos tornaríamos um dos primeiros no ranking de maiores infectados, mortos e, pior, de políticas públicas ineficientes quanto ao tratamento de contenção ao vírus.

Toda essa situação emergencial para o enfrentamento da pandemia implicou em adoção de medidas de caráter econômico, político, social e sanitária nas esferas federais, estaduais e municipais, que tinham como estratégias principais: o distanciamento social, a redução da propagação do vírus por meio de higienização constante e uso de máscaras, tudo para se evitar o colapso do sistema de saúde. Segundo Boaventura de Sousa Santos (2020, s.p.) "deve salientar-se que para os moradores das periferias pobres do mundo, a actual emergência sanitária vem juntar-se a muitas outras emergências". Logo, percebeu-se que havia grande número de pessoas impossibilitadas de cumprirem as medidas orientadas pela OMS.

O Governo Federal na pessoa do Presidente reforçou e reforça ainda hoje a saída do isolamento social nacional como única alternativa de não matar de fome os que são corpos frágeis e descartáveis das e para as suas políticas econômicas que reforçam a morte em contraponto às vidas (BESSAOLIVERIA, 2020). Contrariando esta postura homicida, governadores e prefeitos e até os vários dirigentes institucionais, acercados por leis que lhes 
dão os direitos de decisão e da tomada de decisões - “[...] graças ao STF Supremo Tribunal Federal, em 15 de abril do corrente ano, uma decisão favorável "que garante autonomia a prefeitos e governadores determinarem medidas para o enfrentamento ao coronavírus" (AGÊNCIA SENADO, 2020, on-line)" (BESSA-OLIVEIRA, 2020a, p. 5) -, agiram e, na medida do possível, vêm agindo, também, contra a "pandemia" catastrófica maior, o neoliberalismo capitalista de extrema-direita que assombra igualmente o Brasil (BESSA-OLIVEIRA, 2020, p. 43-44).

Expressões pouco usadas antes passaram a ser repetidas cotidianamente nas conversas, nos documentos oficiais, nas reportagens da TV e rádio, além dos vários canais de informações via internet. Palavras como isolamento social, quarentena e distanciamento social passaram a ser usadas constantemente com seu significado indefinido, ou até mesmo como sinônimos. Consoante André Faro e autores,

A quarentena busca separar e restringir a circulação de pessoas que foram expostas a uma doença contagiosa, visando a observar se estas ficarão doentes. Já o isolamento diz respeito à separação de pessoas doentes, infectadas por alguma doença transmissível, como a COVID-19, dos não doentes (FARO, 2020, p. 4, Grifos meus).

Em pouco tempo houve a necessidade de manter o isolamento social ocasionou o fechamento das escolas no mundo inteiro. No Brasil, a portaria $n^{\circ} 454$ de 20 de março de 2020 do Ministério da Saúde, no Art. $1^{\text {o }}$ afirma que "Fica declarado, em todo o território nacional, o estado de transmissão comunitária do coronavirus (covid-19)”. Escolas de Educação Infantil, Educação Básica e Ensino Superior se viram diante da necessidade primeira de preservar as vidas, entretanto com o grande desafio de continuar o calendário letivo por meio de atividades não presenciais.

Entre algumas idas e vindas, fechamento e abertura de escolas e outras instituições, não somente da área da educação, estados e municípios ficaram acercados de políticas que traziam tratativas localizadas, graças à grande maioria de governadores e prefeitos, que foram vistos como contrários a uma política de Estado-nacional em relação a uma Pandemia que para esse parecia ainda inexistente. A questão agora era, para a educação em nível nacional, como dar continuidade ao trabalho das escolas e professores em relação ao necessário isolamento defendido pelas instituições científicas mundiais?

A portaria $\mathrm{n}^{\circ}$ 343, de 17 de março de 2020 do Ministério da Educação (MEC) dispôs sobre "a substituição das aulas presenciais por aulas em meios digitais enquanto durar a situação de pandemia do Novo Coronavírus - COVID-19”. No dia seguinte, o Conselho Nacional de Educação (CNE), por meio do PARECER CNE/CP Nº: 5/2020, veio a público elucidar aos sistemas e às redes de ensino, de todos os níveis, etapas e modalidades, 
considerando a necessidade de reorganizar as atividades acadêmicas por conta de ações preventivas à propagação da COVID-19.

[...] flexibilizou excepcionalmente a exigência do cumprimento do calendário escolar ao dispensar os estabelecimentos de ensino da obrigatoriedade de observância ao mínimo de dias de efetivo trabalho escolar, desde que cumprida a carga horária mínima anual estabelecida nos referidos dispositivos, observadas as normas a serem editadas pelos respectivos sistemas de ensino (BRASIL, 2020, p. 5).

A partir desse momento, as atividades denominaram atividades remotas, pois associavam as ações não presenciais mediadas ou não por recursos tecnológicos. Foi árduo transpor abruptamente o modelo presencial para um "novo" modelo chamado remoto. Como fazer? Não sabíamos, ninguém sabia. "O método para tal objetivo é “aprender a desaprender, a fim de voltar a aprender”” (MIGNOLO, 2008, p. 323). É fato que a educação teve que se reinventar e incorporar práticas nunca antes necessárias, ou pelo menos, não com tamanha primordialidade. No entanto, é fato também que a escola não é o único lugar que se aprende. Há que se considerar que, quando o estudante vai para o espaço escolar, ele leva consigo diversas habilidades que aprendeu com sua família, com sua comunidade, nos ritos folclóricos, religiosos e em diversos espaços. Assim, percebe-se que, neste tempo de crise, as famílias, os educadores e toda a sociedade necessitam desenvolver a consciência que nos sugere Mignolo na citação anterior, voltando a aprender de forma diferente. Forma esta que não desmerece a necessidade da escola, mas torna as experiências culturais e as interações de corpos culturalmente esquecidos, como o centro dessa nova aprendizagem.

Se por um lado o aprender a desaprender, a fim de voltar a aprender - base do pensamento descolonial - pode parecer descabido no contexto de pandemia em relação à mudança da educação presencial para remota. Por outro lado, é possível dizer que a pandemia se torna, ainda que na pior da situação, uma possibilidade da educação (aprender) transformar-se naquele espaço de produção de conhecimentos e saberes em diálogos. Quando, de uma outra perspectiva (descentralizando da ciência moderna a única produtora de conhecimentos, por exemplo) percebemos que a educação pode ser um campo fértil para diálogos entre seres, sentires e saberes para que todos possam fazer-sendo.

Evidentemente, na tentativa de fazer o melhor possível e dar maiores condições de organização da ação educativa, diversas orientações passaram a ser produzidas pela Secretaria de Educação de Mato Grosso do Sul com a finalidade de auxiliar esse novo momento de caráter excepcional - que já não é tão excepcional assim quando se lembra de que estamos há mais de 1 ano e 4 meses nesta situação. E que é, de algum modo, 
melhor que tenhamos mantido a paralização de tudo. Pois, é certo, a educação ainda é a única opção, estejamos como estamos, de evidenciar que os saberes/conhecimentos são as únicas formas de sobrevida das pessoas.

\section{Mato Grosso do Sul: o ensino remoto na Rede Estadual de Ensino}

No estado do Mato Grosso do Sul, as ações normativas de combate ao coronavírus iniciaram por meio do Decreto $\mathrm{n}^{\mathrm{o}} 15.391$, de 16 de março de 2020, que

Dispõe sobre as medidas temporárias a serem adotadas, no âmbito da Administração Pública do Estado de Mato Grosso do Sul, para a prevenção do contágio da doença COVID-19 e enfrentamento da emergência de saúde pública de importância internacional decorrente do coronavirus (SARS-CoV2), no território sul-mato-grossense.

Neste momento, muitas incertezas pairavam e as ações passaram a ser diariamente atualizadas, e novas decisões eram publicadas frequentemente. No que tange à educação, no Decreto Estadual $n^{\circ} 15.393$, de 17 de março de 2020, foram suspensas as aulas presenciais nas unidades escolares e nos centros da Rede Estadual de Ensino de Mato Grosso do Sul (REE-MS), e sugeriu-se que as Secretarias Municipais de Educação observassem tal orientação. Importante destacar que o período de 18 a 20 de março de 2020 foi destinada a "adaptação para a comunidade escolar", momento este relevante a fim de estabelecer canais de contatos entre escolas e famílias.

No mesmo dia da publicação do Decreto, a Secretária de Estado de Educação, prof ${ }^{a}$ Maria Cecília Amendola da Motta via canal da SED no Youtube $e^{4}$ orientou sobre o período de suspensão das aulas presenciais aos diretores da Rede Estadual de Educação, por restrições relacionadas à COVID-19, e explicou que a Secretaria estava, naquele momento, estudando diversos exemplos mundiais para verificar a melhor aplicabilidade no Brasil e principalmente em Mato Grosso do Sul.

Subitamente fomos pegos de surpresa e colocados em uma situação desconhecida para muitos: lidar com a tecnologia, custasse o que for, para substituir as aulas e demais atividades antes realizadas presencialmente com um número enorme de indivíduos com diferentes especificidades. Vale salientar que o estado se constitui de evidentes diferenças "biogeografias: corpos, espaços e narrativas” (BESSA-OLIVEIRA, 202 1, p. 81) em que as condições de acesso à educação são muito diferentes em contextos normais e tornaram-se ainda maior no enfrentamento à pandemia. Não bastasse sermos o segundo estado com maior população

\footnotetext{
${ }^{4}$ Disponível em:

https://www.youtube.com/watch?v=e8FStZQqDU8\&list=PL6LF4GoutZ2_AtNkyDDeIXWx45zltYTi M\&index $=1$. Acesso em: 04 jun 2021
} 
indígena do país, ainda contamos com fronteiras internacionais, quilombolas, ou seja, um fluxo enorme de brasileiros de diferentes estados e de muitos estrangeiros de diferentes países de todos os continentes. Mato Grosso do Sul é, literalmente, um lugar de trânsito, tráfego e tráfico de saberes, culturas e identidades.

Naquele período, acreditava-se que a pandemia duraria algo em torno de 3 meses, e para melhor atender as demandas apresentadas, foi solicitado às escolas que estabelecessem canais de contato com seus estudantes e seus responsáveis. Essas orientações foram enviadas por meio da Comunicação Interna Circular da SITEC/SED 5 $n^{\circ} 61$ de 18/03/2020, na qual acreditava-se que o impacto do coronavírus não seria duradouro. ${ }^{6} \mathrm{Na}$ mesma época na China (onde supostamente tudo começou), as crianças estavam sem aulas presenciais há pouco mais de um mês. A comunicação, entretanto, orientava que, "caso os tempos se prolonguem, haverá necessidade da adoção de algumas estratégias, como o uso de recursos tecnológicos”, buscando manter o aprendizado e o aproveitamento dos estudantes da REE-MS.

Assim, solicita-se que os senhores estabeleçam canais de comunicação rápida
com os seus professores (whattsApp, e-mail, etc.), visando à formação
autoinstrucional destes no que se refere ao uso dessas tecnologias, para
continuar garantindo aos estudantes o direito a uma educação igualitária e
inclusiva para todos.
É de extrema importância que orientem os seus professores para que também
definam esses canais de comunicação com todos os estudantes e com todas
suas turmas e possam fazer a distribuição dos conteúdos, bem como das
atividades, no período em questão. ${ }^{7}$

A esta altura iniciou-se uma corrida contra o tempo para a criação de grupos de WhattsApp e elaboração de atividades para serem repassadas aos estudantes de todo o território do estado. Os professores não estavam preparados para esse período de suspensão de aulas presenciais, tampouco os estudantes para permanecerem em casa, mantendo a rotina escolar em ambiente familiar. Todos foram surpreendidos diante da crise pandêmica, inclusive o Estado brasileiro.

Contraditório! Mas que são corpos que, aliás, já são tecnocolonizados - haja vista que vivemos, assim como sob à colonização, ao patriarcado e submissos ao capitalismo que são presentes e quase inevitáveis dada a modernidade -,

\footnotetext{
${ }^{5}$ SITEC/SED: Superintendência de Informação e Tecnologias da Secretaria de Estado de Educação de MS.

${ }^{6}$ Num primeiro momento até os estados e municípios que viram mais tarde contrapor ao Governo Federal acreditavam na brevidade da pandemia. Entretanto, como já ressaltado, os números mostram que mesmo com todo o trabalho braçal da Saúde Pública brasileira, de governadores e prefeitos, na sua grande maioria, o Governo Federal tornou-se o maior rival da atuação contra a Pandemia: "receitando" medicamentos sem eficácia contra o vírus, cientificamente comprovada, contrariando as medidas protetivas e desacreditando o vírus, chegamos muito mal onde estamos.

7 Disponível em: http://www.cee.ms.gov.br/wp-content/uploads/2020/o4/CI-SITEC-61.pdf. Acesso em: 04 jun 2021.
} 
vivemos também imersos em uma tecnocolonialidade que resulta daqueles padrões modernos agora neoliberais, mas que se constituem hoje como frutos das relações entre tecnologia $=$ economia $=$ virtualidade versus corporeidade $=$ sensibilidade/subjetividade $=$ convivialidade: todxs para o controle sobre os corpos das diferenças coloniais (tecnocoloniais, vamos dizer assim agora). (BESSA-OLIVEIRA, 2020, p. 74)

Naquele momento sequer descobrimos a tecnocolonização que mais ainda pairaria sobre nós. Dependentes totalmente de aparatos tecnológicos, fomos conduzidos para um mundo que muitos de nós não dominamos/acessamos, ou que não sabemos se um dia teremos a possibilidade de acessar. Dada a falta de tudo que a educação tecnológica requer, muitas escolas, estudantes, professores e familiares foram ainda mais colocados em situação de exclusão pela falta de acessos, ainda que precários, à educação escolar.

$\mathrm{Na}$ sequência dos documentos oficiais expedidos pelo Governo do Estado de MS, o Decreto Estadual n. 15.395, de 19 de março de 2020, institui o Regime Excepcional de Teletrabalho no âmbito da Administração Pública do Estado de Mato Grosso do Sul. Assim, boa parte dos funcionários públicos estaduais (exceto aqueles considerados essenciais) atuaram em regime de teletrabalho (ou como conhecido - home office) ou alternavam em escala presencial, com a finalidade de diminuir o trânsito e a aglomeração de pessoas, salientando que “é necessário que o servidor disponha de acesso à internet e de equipamentos de informática e de comunicação para a perfeita execução de suas atividades, [...]”.

"Nesse sentido, inicialmente, tornou-se evidente um necessário aparato tecnológico para a sobrevivência de docentes e discentes” (BESSA-OLIVEIRA, 2020, p. 13-14). E não só para professores e seus alunos, mas também para diretores, coordenadores pedagógicos, familiares e responsáveis dos estudantes, assim como para toda equipe técnico-pedagógicos da SED-MS.

Na SED-MS, especificamente no setor pedagógico, o trabalho essencial focou na mínima condição de manter o ano letivo em curso, com as "Atividades Pedagógicas Complementares” regulamentadas pela Resolução SED-MS n. 3.745, de 19 de março de 2020.

Art. $1^{\circ}$ Para cumprimento da carga horária anual e dias letivos aos quais o estudante tem direito, conforme legislação, nas escolas da Rede Estadual de Ensino será ofertada Atividade Pedagógica Complementar - APC, durante o período de suspensão das aulas presenciais prevista no Decreto n. 15.391, de 16 de março de $2020 .{ }^{8}$

E ainda, na Instrução Normativa n. 5 da Superintendência de Políticas Educacionais/SED, que em seu Art. $2^{\circ}$ define que,

\footnotetext{
8 Disponível em: http://www.cee.ms.gov.br/wp-content/uploads/2020/04/Di\%C3\%A1rio-Oficial-resolucao3745.pdf. Acesso em: 04 jun 2021.
} 
Compete à Direção Escolar estabelecer, em conjunto com a equipe técnicopedagógica, o modo de comunicação com o estudante, se maior de idade, ou pai/mãe ou responsável, se menor de idade, a fim de garantir o envio e recebimento das Atividades Pedagógicas Complementares - APC, a serem realizadas pelo estudante no período de suspensão das aulas presenciais, conforme estabelecido em legislação.

$\S 1^{\circ} \mathrm{O}$ modo de comunicação a ser estabelecido pode ser físico ou virtual, dependendo das condições de acesso do estudante, priorizando os meios de comunicação não presencial, a fim de evitar a circulação de pessoas na escola. $\S 2^{\circ}$ A distribuição aos estudantes e os prazos de entrega e recebimento da APC serão de responsabilidade da equipe técnico-pedagógica da escola.

Aqui se inicia então o complexo período de atividades remotas executadas pelos docentes e discentes da Educação Básica de MS: sujeitos do processo de aprendizagem de diferentes contextos sociais, cidades, periferias urbanas, terras indígenas, comunidades do campo, assentamentos, comunidades descendentes de quilombolas entre tantas “diversalidades" existentes neste estado. Abruptamente, todos, sem exceção, tornaram-se professores, estudantes e familiares ao mesmo tempo dentro de suas próprias casas. Transmutamos de um processo de humanização, tão defendido na educação, para um projeto de objetificação, nascido na Era Moderna ainda insistente na contemporaneidade.

[...] aos indivíduos da exterioridade, a opção de pertencimento biogeográfico em um mundo marcado pela colonialidade do poder, prevalecida a partir da razão colonial moderna (sec. XVI), que fez a separação de corpos da diferença entre humanidade e objeto a partir das classificações dos diferentes por categorias de raça, classe e gênero. (BESSA-OLIVEIRA, 2019, p.64).

Essas categorias descritas estão presentes nas escolas da REE-MS, inúmeras famílias em contexto de vulnerabilidade social, sem recursos financeiros para aquisição de aparatos tecnológicos, sem acesso à internet ou com acesso limitado, este talvez, por estar relacionado à indisponibilidade de rede em suas localidades. Famílias que dependem do transporte escolar para que seus filhos e filhas possam frequentar as escolas. Como esses estudantes teriam acesso às chamadas APCs das aulas remotas?

Observando os professores da REE-MS, esses se viram em meio à diferentes situações impostas e necessárias à continuidade do ano letivo, imbricados em tecnologias em tempo integral, planejando, avaliando, aprendendo, (re)planejando, (re)avaliando e aprendendo algo novo, como um ciclo ininterrupto e cada vez mais isolado do mundo real.

[...] professores e estudantes enfrentam uma vilã para muitos e uma solução para vários: a própria tecnologia. Dirigentes têm trabalhado para atender as demandas oriundas de estudantes e professores, atendidos ou não pelo acesso às tecnologias. Técnicos têm se virado em esforços hercúleos para atender situações inusitadas demandadas por professores, discentes e dirigentes que são, na verdade, novidade inclusive para eles, em situação de trabalho remoto. Professores e estudantes têm, diária, 
quase diuturnamente, se "debatido", "embatido", convivido, isolado, por meio de ambientes virtuais, impressos, por telecomunicação, quase que por sinal de fumaça, a fim de travar diálogos de conhecimentos em prol do fatídico conteúdo didático das diferentes disciplinas e séries que agora vão seguir vias diferentes tecnologias. (BESSA-OLIVEIRA, 2020, p. 21-22)

Especialmente falando dos professores da REE-MS, grande parte deles tiveram que aprender sozinhos a utilizarem as tecnologias eletrônicas e consequentemente ministrarem suas aulas, ou minimamente fazê-las chegar aos seus estudantes. Tal situação gerou medo, sentimento de incapacidade, frustração, entre outros sentimentos que vieram à tona. Sem contar dos efeitos físicos nos corpos ocasionados por permanecerem sentados por muito tempo em frente ao computador.

[...] a tecnocolonialidade a meu ver do/no corpo na arte, na cultura e na Educação aqui em debate, de agora em diante, tem a ver com aquela questão da epígrafe de Quijano - de que há uma crise que é ressaltada aos corpos latinoamericanos pela sua mais antiga história pós-colonial; genocídios, escravização, colonialismo -, mas, na atualidade, está imperante nesses corpos Latinos (e latino aqui engloba toda a má sorte de sujeitos não-europeus, por exemplo, que desgraçam na exterioridade ao projeto moderno europeu) que não são respeitados pela colonialidade do poder globalizante da tecnologia que finge incluir quando, na verdade, especialmente no caso brasileiro, mata pela exclusão ou submete o corpo à racialização e construção do outro como um ser etnográfico, na produção artística, na cultura e na produção de conhecimentos para manutenção dos padrões históricos e contemporâneos (geo, ego e políticos) de poder. (BESSA-OLIVEIRA, 2020a, p. 15).

É bem verdade que a SED-MS se esforçou para orientar as ações pedagógicas, buscou importantes parcerias com o objetivo de disponibilizar salas de aulas virtuais a todos os estudantes e professores da REE-MS. Além disso, disponibilizou vários cursos, webinários e formações online com a finalidade de dar suporte ao trabalho docente, seja no campo pedagógico curricular, como nas questões socioemocionais. No entanto, com tantas reuniões, aulas, lives, cursos, formações, grande parte dos professores se sentiram cada vez mais esgotados, cansados e frustrados. E ainda há de se levar em consideração a jornada doméstica com todos em casa.

Assim, não podemos deixar de comentar neste estudo quanto à saúde mental dos professores. Acostumados ao amplo envolvimento com os estudantes em seu dia a dia, professores vêm sentindo o peso das aulas remotas e estão adoecendo silenciosamente, recolhidos em suas casas.

Adicionalmente a um cenário de crise, considerado por si só um agente estressor, inúmeros docentes vêm adoecendo física e mentalmente em silêncio, como consequência da pressão para atingir os objetivos impostos pelos gestores, da culpabilização pela inadequada estrutura das instituições de ensino e da evasão dos estudantes. (SANTOS, SILVA, BELMONTE, 2021, p. 246). 
Não é raro encontrar professores e gestores escolares frustrados e desanimados com o ensino remoto. Preparar as atividades síncronas tem despertado uma sensação de fracasso, pois, a participação esperada muitas vezes não acontece. Os estudantes simplesmente não aparecem.

\begin{abstract}
A ausência da interação e da relação interpessoal natural e física, face a face, bem como a ação de desativar câmera e áudio em videoconferências, consolida a lógica unidirecional do ensino e aumenta ainda mais a percepção dos professores de estarem falando sozinhos. (SANTOS, SILVA, BELMONTE, 2021 , p. 247).
\end{abstract}

Ao adentrar as residências de professores e estudantes, o ensino remoto tirou a privacidade de ambos. O período, que antes era destinado para estar em casa para o repouso e a vida familiar, foi invadido pelo "home office" e tal situação tem deixado muitos educadores esgotados mentalmente. Tamanho esgotamento, em partes, se deve ao não domínio dos recursos tecnológicos, por terem suas vidas pessoais misturadas com as profissionais, e além disso, pelo distanciamento de pessoas e atividades diárias que evitariam muitos desses silêncios que fazem com que os professores enfrentem seus medos, angústias e frustrações sozinhos, nas invisibilidades.

Outra situação que não podemos esquecer e que causa muita angústia nos professores é em relação à evasão escolar. Segundo dados da PNAD (2019 apud UNICEF, 202 1, p. 48) em Mato Grosso do Sul são 28.869 crianças e adolescentes entre 6 e 17 anos que estão fora da escola, totalizando $5,7 \%$ da população desta faixa etária. Por esse motivo, é necessário imprescindível intervir ainda mais com políticas públicas estaduais para dirimir a exclusão escolar potencializada pela pandemia da COVID-19.

As fronteiras desses fazeres artísticos que estão emergindo da situação de
pandemia também vinham antes desta acercadas da referência teopolítica e da
geopolítica como vim mostrando até aqui. Evidentemente considerando as
políticas públicas hoje de arte, de cultura e para a produção de conhecimento no
Brasil, por exemplo, que não são arte, cultura e conhecimentos em políticas,
que sequer têm políticas de arte, de cultura e de conhecimentos, claramente essas
vinham muito mal. (BESSA-OLIVEIRA, 2020b, p. 128-129, grifos meus)

Pensar no futuro da educação é renunciar a pensamentos individuais para pensar coletivamente. Pensar nos (e não para) diversos meninos e meninas excluídos, invisibilizados e ignorados do sistema educacional simplesmente por fazerem parte de uma categoria chamada de vulneráveis, “[ [..] é a diferença colonial, entendida como pensar a partir das ruínas, das experiências e das margens criadas pela colonialidade do poder [...]” (OLIVEIRA; CANDAU, 2010, p. 23). 
Se o Brasil, cada um de seus estados, cada município, cada escola, cada família, cada criança e cada adolescente pôde conviver com a exclusão até aqui, o cenário imposto pela pandemia a intensifica e exige medidas que busquem o seu enfrentamento. (UNICEF, 2021, p. 51).

A exclusão escolar tem origem nos contextos socioeconômicos e culturais e esses se reproduzem nas escolas. As demandas cotidianas e/ou as limitações impostas são as principais causas para que crianças e adolescentes em idade escolar obrigatória deixem de estudar. Assim, o Estado tem função primordial neste contex to - oferecer educação de qualidade e equidade para todos. E não é falarmos de uma educação minimamente possível. Mas sim, falar em ofertar a melhor educação pública pela qual a sociedade paga muito caro por ela com os altos impostos brasileiros cobrados.

Ao falar da exclusão escolar, não podemos esquecer das crianças e adolescentes sem acesso (ou com acesso precário) à recursos tecnológicos e que agora estão também sem acesso às escolas, à convivência entre pares, à aprendizagem e à alimentação - haja vista que muitas crianças brasileiras (e na América Latina) necessitam da alimentação escolar para sobreviverem.

Dessarte, não distante da nossa realidade, o ensino remoto provocou diferenças coloniais imensas, pois onde falta tudo, agora também falta o contato com a escola, a aprendizagem pela interação coletiva, as conversas afáveis em que se fala sobre a vida e se identifica problemas. A escola como instituição de ensino pode até ser substituída pelas atividades remotas da melhor maneira possível, mas esta mesma escola como instituição social, não pode ser substituída por recursos tecnológicos, tampouco por materiais impressos.

\section{O que será necessário à educação?}

A Pandemia da COVID-19 tem evidenciado que os corpos "considerados normais" não estão sabendo lidar com o "novo normal” que se apresenta. Professores não podem ou não devem, pelo olhar colonial, sofrer, seja por não conseguirem entender ou resolver o problema da educação em meio a pandemia, seja por medo do vírus ou pela frustração diante da condição atual vinculado ao ato de ensinar. Sentem-se “um corpo estranho” neste novo cenário educativo.

[...] meu/nosso corpo estranho, o que temos e é dele/nele que somos, está articulado a partir dessa condição de exterioridade de imposição colonial, mas também toma da colonialidade do poder imperante ainda nas culturas contemporâneas para discutir a condição deste corpo estranho na cultura, a partir de seu bios e na situação atual da educação (FARIA; BESSA-OLIVEIRA, 2019, p. 7-8). 
Muitos legados devem ser considerados na educação pós-pandemia, pois esta necessitou repensar e reformular práticas educativas antes não imaginadas nas políticas, nas crenças, nos costumes, nas universidades que preparam os professores para a docência. Todos, educadores e educandos, visualizando suas "razões de ser, sentir e saber para fazer o que o pensamento moderno não considerou e que a pós-modernidade e muitos casos na contemporaneidade tentaram descartar" (BESSA-OLIVEIRA, 2021, p. 1983).

Acredita-se e espera-se que, na educação pós-pandemia, as aulas tradicionais e mais expositivas diminuam, que os estudantes tenham seus espaços garantidos como protagonistas da aprendizagem, tornando-os mais ativos na busca pelo conhecimento, sejam ouvidos, acolhidos e tratados em suas individualidades. Que a educação integral, premissa da REE-MS, seja verdadeiramente colocada em prática, para a construção e promoção do Projeto de Vida de cada estudante.

Aquela máxima do pensamento descolonial - aprender a desaprender, a fim de voltar a aprender - talvez seja a premissa primeira de uma educação pós-pandemia que primará pelos conhecimentos dos estudantes como a base para a formação de uma educação de qualidade com equidade para todos da/na educação.

\section{Considerações finais}

A educação brasileira, em especial, está passando por dias obscuros. Em Mato Grosso do Sul não é diferente. Os difíceis protocolos de biossegurança impostos pelo enfrentamento da pandemia da COVID-19 impuseram aos professores horas de trabalho extras para atenderem às demandas educacionais. A pandemia nos mostrou que, assim como os supostos bens do primeiro-mundo, todos os malefícios, de agora em diante, também nos afetarão.

Manusear recursos tecnológicos passou a ser um desafio diário, mesmo para aqueles que já se valiam desses recursos em sala de aula, estes passaram a ser questão de sobrevivência profissional. A pandemia evidenciou o problema da falta de domínio para sua utilização, mas também a ausência da tecnologia passou a ser problema para os professores, motivo pelo qual muitos de seus estudantes simplesmente sumiram das aulas remotas e/ou virtuais.

Professores passaram a trabalhar mais tempo, atendendo estudantes fora do horário de trabalho. Mas como não seria assim se os estudantes os procuram em outros momentos por diversos motivos: falta de compromisso, internet, equipamento, auxílio, entre tantas outras faltas nesse processo em que a educação, ou o ato de ser educador tornou-se também um ato de confissão.

Além dos impactos psicológicos diretamente relacionados pelo excesso de trabalho devido à pandemia da COVID-19, ainda temos que considerar os abalos psicossociais causados 
pelas medidas preventivas, com os efeitos da quarentena e do isolamento social, que não só nos deixaram mais tempo dentro de casa, mas nos impediram de momentos de lazer e entretenimento. Nos deixaram mais vulneráveis aos problemas de convívio doméstico e aos cuidados com a saúde do corpo causando ansiedade, depressão e outros fatores de risco à saúde mental e bem-estar emocional.

Não podemos negar que as aulas remotas podem contemplar, da melhor forma possível que for, o que só teríamos por aulas presenciais, mas necessitamos salientar a imprescindibilidade de equidade nos processos educacionais antes, durante e principalmente depois da pandemia. A escola não é o único lugar em que se aprende, mas é um lugar muito importante para se desenvolver competências e habilidades acadêmicas.

Por fim, lembramos que o número de crianças e adolescentes fora da escola já era considerado alto em 2019. Com a suspensão das aulas presenciais, estima-se que mais de 5 milhões de crianças e jovens, entre 6 e 17 anos não frequentaram ou não realizaram atividades escolares durante o ano letivo de 2020. Esta ausência de atividade escolar afeta a saúde, o desenvolvimento, a segurança e o bem-estar desses. Os mais vulneráveis (como sempre) sofreram/sofrerão o maior impacto.

Contudo há necessidade de se aprofundar as pesquisas, discussões e reflexões acerca das consequências de pandemias na aprendizagem escolar das crianças e adolescentes de Mato Grosso do Sul e do Brasil, pois neste momento, muitas perguntas ainda ficarão sem respostas. Quando retornaremos às aulas presenciais? Como os professores e estudantes estarão quando o reencontro acontecer? Como retornar as atividades pensando na recuperação das aprendizagens não consolidadas pelos estudantes e na valorização das muitas habilidades adquiridas? Como estão as saúdes mentais dos professores e estudantes? Entre outras perguntas, percebe-se que muito ainda terá que ser estudado para ser respondido. É preciso pensar inclusive a tecnocolonização na educação brasileira. Muitas serão nossas ações para que a educação em Mato Grosso do Sul possa ser reestabelecida, não como estava, mas com olhares ao professor e ao estudante que trazem suas histórias, seus medos, seus lutos, suas lutas. Enfim trazem vidas vividas para a escola.

\section{Referências}

BESSA-OLIVEIRA, M. A. arte-educação descolonial: formação de professor de arte para um trabalho docente mediador. In: Revista Educação - UNG-Ser, Campinas, SP, v. 16, n. 1, p. 1980-6469, 2021. DOI: 10.33947/1980-6469-V16N1-4133. Disponível em: http://revistas.ung.br/index.php/educacao/article/view/4133/3264. Acesso em: 04 jun. 2021. DOI: https://doi.org/10.33947/1980-6469-v16n 1-4133. 
BESSA-OLIVEIRA, Marcos Antônio. Educação, Tecnocolonialidade, docência remota Ẽ a COVID-19. Campo Grande MS, Editora Life, 2020.

BESSA-OLIVEIRA, Marcos Antônio. O Corpo e a Geopolítica da Tecnocolonização, Tecnocolonialidade do Corpo na Arte, na Cultura e na Educação! ( ${ }^{a}$ Parte). Artigo apresentado no II Congresso Internacional Online de Estudos sobre Culturas, na modalidade online, 2020. Foz do Iguaçu, PR, Online, 22 a 26 de junho, p. 1-21, 2020a. (Texto acervo do autor).

BESSA-OLIVEIRA, Marcos Antônio. Arte Biogeográfica, Processos Criativos E̊ a Covid-19. Campo Grande MS, Editora Life, 2020b.

BESSA-OLIVEIRA, Marcos Antônio. Pedagogias da diversalidade. In: Cadernos de Estudos Culturais, Campo Grande, MS, v. 1, p. 61-86, jan./jun., 2019. Disponível em:

https://desafioonline.ufms.br/index.php/cadec/article/view/9691. Acesso em: 04 jun. 2021.

BRASIL; PARECER CNE/CP N : 5/2020. Disponível em:

http://portal.mec.gov.br/index.php?option=com_docman\&view $=$ download $\& a l i a s=145011-$ pcp005-20\&category slug=marco-2020-pdf\&Itemid=30192. Acesso em: 13 jun. 2021.

BRASIL; PORTARIA $N^{\circ}$ 454, DE 20 DE MARÇO DE 2020. Disponível em: https://www.in.gov.br/en/web/dou/-/portaria-n-454-de-20-de-marco-de-2020-249091587. Acesso em: 13 jun. 2021.

DE SOUSA SANTOS, Boaventura. A cruel pedagogia do vírus. Boitempo Editorial, 2020.

FARIA, J. R.; BESSA-OLIVEIRA, M. A. Meu/nosso corpo estranho, o que temos é dele/nele que somos: cultura, bios, educação. In: Filosofia e Educação, Campinas, SP, v. 1 1, n. 1, p. 5-35, 2019. Disponível em:

https://periodicos.sbu.unicamp.br/ojs/index.php/rfe/article/view/8655077. Acesso em: 4 jun. 2021 . DOI: https://doi.org/10.20396/rfe.v11i1.8655077.

FARO, ANDRÉ ET AL. COVID-19 e saúde mental: a emergência do cuidado. In: Estudos de Psicologia (Campinas) [online]. 2020, v. 37, e200074. Disponível em:

https://www.scielo.br/j/estpsi/a/dkxZ6QwHRPhZLsR3z8m7hvF/?lang=pt. Acesso em: 12 jun. 2021.

MATO GROSSO DO SUL. SECRETARIA DE ESTADO DE EDUCAÇÃO.

Comunicação Interna Circular (CIC) da SITEC/SED no 61. Orientações SITEC. 2020.

Disponível em: http://www.cee.ms.gov.br/wp-content/uploads/2020/04/CI-SITEC-

61.pdf. Acesso em: 04 jun. 2021.

MIGNOLO, Walter. Desobediência epistêmica: a opção descolonial e o significado de identidade em política. In: Cadernos de Letras da UFF-Dossiê: Literatura, língua e identidade, v. 34, p. 287-324, 2008. Disponível em:

https://edisciplinas.usp.br/pluginfile.php/4251728/mod_resource/content/o/op\%C3\%A 7\% C3\%A30\%20descolonial\%20walter\%20mignolo.pdf. Acesso em: 20 jun. 2021.

OLIVEIRA, Luiz Fernandes de; CANDAU, Vera Maria Ferrão. Pedagogia decolonial e educação antirracista e intercultural no Brasil. In: Educação em revista, v. 26, n. 1, p. 15-40, 2010. Disponível em:

https://www.scielo.br/j/edur/a/TXxbbM6FwLJyh9G9tqvQp4v/?lang=pt. Acesso em: 02 jun. 2021 . DOI: https://doi.org/10.1590/s0102-46982010000100002. 
OPAS, Organização Pan-Americana da Saúde, 2020, Histórico da pandemia de COVID-19. Disponível em: https://www.paho.org/pt/covid19/historico-da-pandemia-covid-19. Acesso em: 13 jun. de 2021.

SANTOS, Geórgia Maria Ricardo Félix dos; SILVA, Maria Elaine da; BELMONTE, Bernardo do Rego. COVID-19: ensino remoto emergencial e saúde mental de docentes universitários. In: Revista Brasileira de Saúde Materno Infantil, v. 21, p. 237-243, 2021. Disponível em:

https://www.scielo.br/j/rbsmi/a/b3TVbVHcCZRxkVZPFPK6PHF/?lang=pt. Acesso em: 13 jun. 2021 . DOI: https://doi.org/10.1590/s1519-38292003000200001.

UNICEF, Fundo das Nações Unidas para a Infância. Cenário da Exclusão Escolar no BrasilUma alerta sobre os impactos da pandemia da COVID-19 na Educação. 2021. Disponível em: https://www.unicef.org/brazil/media/14026/file/cenario-da-exclusao-escolar-nobrasil.pdf. Acesso em: 17 mai. de 2021. 